Recebido em: 16-03-2017 Aceito em: 05-05-2017

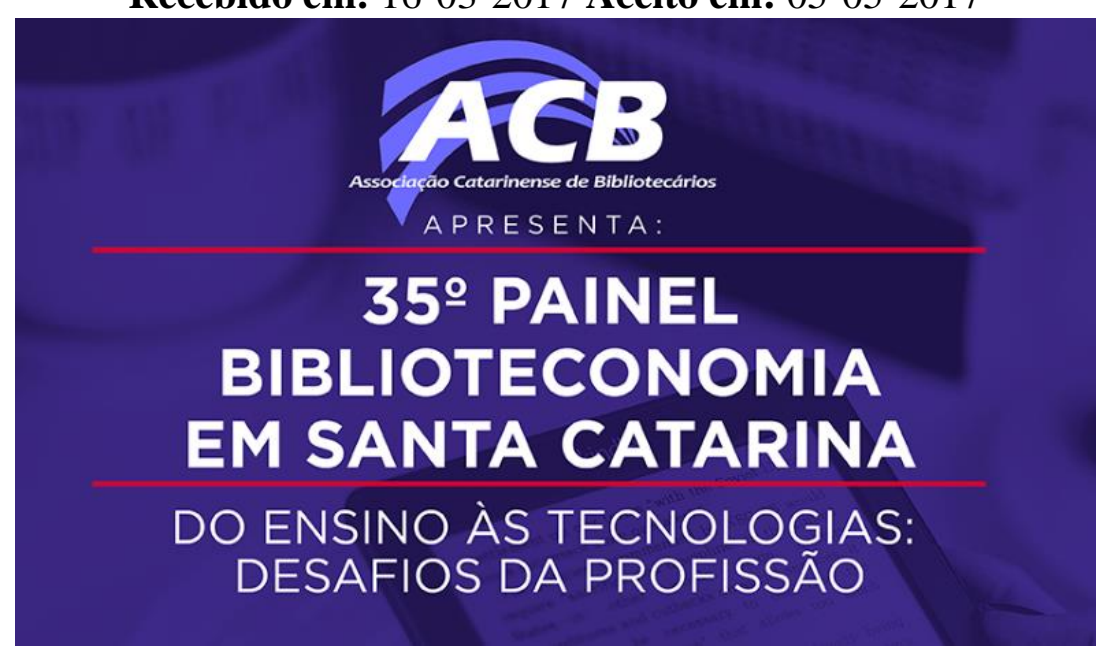

\title{
A COMPETÊNCIA EM INFORMAÇÃO JURÍDICA DOS BIBLIOTECÁRIOS DE FLORIANÓPOLIS, SC
}

\author{
Genilson Geraldo ${ }^{1}$ \\ Elizete Vieira Vitorino ${ }^{2}$
}

\begin{abstract}
Resumo: O extenso e diversificado número de documentos jurídicos e sua complexidade, representam desafios para os profissionais da informação e, consequentemente, exigem formação adequada, dedicação ao trabalho e técnicas apuradas da biblioteconomia, visando a organização, disseminação, qualidade no serviço prestado, ou seja, a competência em informação. Neste sentido, esta pesquisa tem como finalidade investigar a competência em informação na área jurídica, no mercado de trabalho de Florianópolis, SC. Como referência teórica para fundamentar o tema abordado foram utilizados os temas: informação jurídica, perfil e atuação do bibliotecário da área jurídica, e competência em informação. Trata-se de uma pesquisa com abordagem quantitativa e também qualitativa, descritiva, exploratória e bibliográfica. Adotou-se a aplicação de um questionário aos bibliotecários da área jurídica de instituições públicas e privadas. Conclui-se que o perfil do bibliotecário da área jurídica atuante no município de Florianópolis, SC é constituído pela formação, capacitação e experiência vivenciada em sua atuação em informação jurídica. Constatou a carência e a importância do recém-formado em Biblioteconomia, na necessidade da atenção da academia quanto à formação e ao aprimoramento do bibliotecário jurídico.
\end{abstract}

Palavras-chave: Informação Jurídica. Bibliotecário Jurídico. Competência em Informação. Mercado de Trabalho.

\section{INTRODUÇÃO}

A formação do bibliotecário no Brasil é, segundo Passos e Barros (2009), bastante genérica, tendo em vista que, em tese, habilita o profissional a trabalhar em qualquer tipo de serviço de informação. Entretanto, a realidade brasileira mostra que cada área de atuação na Biblioteconomia diligencia conhecimentos específicos.

De acordo com Silva (2010), o estudante de Biblioteconomia e/ou profissional graduado interessado em se especializar em informação jurídica não encontrará atualmente muitas opções de cursos

\footnotetext{
${ }^{1}$ Graduando do Curso de Biblioteconomia do Centro de Ciências da Educação da Universidade Federal de Santa Catarina (UFSC).

${ }^{2}$ Doutora em Engenharia de Produção pela Universidade Federal de Santa Catarina (UFSC).
} 
Revista ACB: Biblioteconomia em Santa Catarina, Florianópolis, v. 22, n. 2, ESPECIAL, p. 238-256, abr./ jul., 2017. Anais do $35^{\circ}$ Painel Biblioteconomia Santa Catarina.

Chapecó

de especialização em Biblioteconomia específicos para a área jurídica. Por muitas vezes, o bibliotecário jurídico completa sua formação no trabalho diário quando apreende as noções básicas do Direito e seu próprio e vasto vocabulário. Isto posto, devido à complexidade e à infinidade de conceitos presentes na documentação jurídica, “é imprescindível que o profissional da informação tenha habilidades técnicas inerentes às bases teóricas da Biblioteconomia e na coabitação dos conceitos vinculados ao Direito". (SILVA, 2010, p. xii). É a competência em informação necessária para a realização dos serviços biblioteconômicos em informação jurídica. Para Beluzzo e Feres (2015 p. 1), “[...] a competência em informação, enquanto competência funcional nos dias atuais torna-se um instrumento crucial para plena integração social". Desta forma, seu desenvolvimento proporciona capacitação dos envolvidos para o acesso, a seleção, a gestão e a avaliação das informações indispensáveis à vida profissional, em especial ao bibliotecário.

Considerando-se que o bibliotecário é um gestor da informação, evidencia-se que a competência em informação jurídica, pode ser investigada ao abordar-se a atuação deste profissional na área jurídica. Isto pode ser obtido sob diversas formas, mas a que adotamos neste trabalho ocorreu por meio de experiências de alguns bibliotecários do município de Florianópolis, SC, focando na competência em informação e em suas práticas profissionais na gestão da informação jurídica, relacionando-se os resultados às demandas do mercado de trabalho na área jurídica florianopolitano.

Portanto, este artigo retrata o perfil profissional de bibliotecários de Florianópolis, SC, atuantes nas bibliotecas, escritórios e assessorias jurídicas, tanto em órgãos públicos quanto em iniciativas privadas, explorando conceitualmente a competência em informação com o apoio das experiências dos bibliotecários, obtidas por meio de questionário aplicado a estes profissionais.

Posto isto, o presente trabalho contempla o ofício do profissional bibliotecário na gestão de informação jurídica, ressaltando a competência em informação nesta área de atuação.

\section{COMPETÊNCIA EM INFORMAÇÃO}

Por meio de pesquisas em bases de dados da área da Biblioteconomia é perceptível que nos últimos anos há um crescente número de produções científicas sobre competência em informação.

Tendo em vista que, atualmente, "abriu-se um foco de compreensão mais abrangente para o termo Competência em Informação e, é possível vê-lo cada vez mais associado à noção de cidadania" (MELO; ARAÚJO, 2007, p.188). Ou seja, algo intrínseco nos trabalhos biblioteconômicos, pois “[...] além de uma série de habilidades e conhecimentos, a noção de valores ligados à dimensão social e situacional”. (DUDZIAK, 2003, p. 30) 
Revista ACB: Biblioteconomia em Santa Catarina, Florianópolis, v. 22, n. 2, ESPECIAL, p. 238-256, abr./ jul., 2017. Anais do $35^{\circ}$ Painel Biblioteconomia Santa Catarina.

Chapecó

Corroborando, a competência em informação no contexto social atual, Belluzzo e Feres (2015) destaca, que:

[...] a questão da competência em informação, como sendo uma área em que o processo de ensino e aprendizagem deve centrar-se por se constituir em processo contínuo de interação e internalização de fundamentos conceituais, atitudinais e de habilidades específicas como referências à compreensão da informação e da sua abrangência [...]. (BELLUZZO; FERES, 2015 p.29)

Pode-se perceber que tanto as habilidades (vinculadas à técnica), quanto a visão crítica (vinculada à ética) estão presentes neste conceito, o que também evidencia uma atuação profissional complexa. De acordo com Miranda (2004, p. 106), competência profissional "está centrada na mudança de comportamento social dos seres humanos em relação ao trabalho e à sua organização". Ou seja, não está relacionado à qualificação para o emprego, e sim "da competência de um indivíduo manifestada e avaliada na sua utilização em situações profissionais" (MIRANDA, 2004, p,106).

A lógica da competência está ligada a três conceitos essenciais, conforme indica Zarifian (2001 apud MIRANDA, 2004 p. 107): o evento, sendo que o trabalho não está mais ligado as situações regulares do cotidiano, e sim aos acontecimentos inesperados; a comunicação, tornando essencial para resolução de problemas no trabalho; e o serviço, gerado por consequência de um trabalho.

A competência profissional configura-se, assim, como “[...] um processo de ativação de recursos, de reunião de condições favoráveis à realização e de superação dos possíveis obstáculos" (MIRANDA, 2004, p.107).

Relacionando competência à informação, pode-se dizer que sua concepção está focada nos tipos de sistemas e no acesso proporcionado, visando assim, o aprendizado integrado ao mecanismo de busca disponibilizado e, consequentemente, ao uso da informação em ambientes físicos e eletrônicos. Elucidando o termo "informação", Smit e Barreto (2002), a definem como "estruturas simbolicamente significantes com a competência de gerar conhecimento área o indivíduo e para o seu meio". (SMIT; BARRETO, 2002, p. 18).

Desta forma, conforme apontam Vitorino e Piantola (2009) a competência em informação, dentro de uma perspectiva crítica, deve ser entendida como uma "arte", pois vai desde o saber fazer e usar a informação até a reflexão crítica sobre a natureza da informação, dentro de seu contexto e impacto social, cultural e até mesmo filosófico.

\subsection{Competência do profissional bibliotecário jurídico}


Revista ACB: Biblioteconomia em Santa Catarina, Florianópolis, v. 22, n. 2, ESPECIAL, p. 238-256, abr./ jul., 2017. Anais do $35^{\circ}$ Painel Biblioteconomia Santa Catarina.

Chapecó

A competência do profissional bibliotecário jurídico depende das atividades exercidas. Alguns profissionais podem exercer múltiplas funções e responsabilidades, que podem exigir especializações, conforme o contexto laboral e institucional que está inserido.

Corroborando com esta afirmação, Vitorino (2009) descreve que:

Competência é o conjunto de conhecimentos, qualidades, capacidades e aptidões que habilitam para a discussão, a consulta, a decisão de tudo o que concerne o trabalho, a qual supõe conhecimentos fundamentados, acompanhados das qualidades e da capacidade que permitem executar as decisões. (VITORINO, 2009, p.132).

Nesse sentido, Passos (2005) apresenta a competência do bibliotecário jurídico estabelecida pela American Association of Law Libraries (AALL) em março de 2001, e expõe que o profissional deve:

a) demonstrar forte compromisso com a excelência do serviço ao cliente;

b) reconhecer a diversidade dos clientes e da comunidade;

c) entender e apoiar a cultura e o contexto da biblioteca e das instituições similares;

d) demonstrar conhecimento do sistema legal e da profissão jurídica;

e) entender o contexto sócio-econômico-político em que o sistema legal existe;

f) demonstrar conhecimento da teoria da Ciência da Informação e do ciclo documentário;

g) aderir aos princípios éticos da AALL, apoiar e compartilhar dos valores da Biblioteconomia;

h) exibir habilidades de liderança, incluindo pensamento crítico, tomada de risco, independentemente de sua posição na estrutura administrativa;

i) demonstrar compromisso com o trabalho em grupo para alcançar objetivos comuns;

j) agir dentro da organização para implementar os princípios do conhecimento administrativo;

k) exibir compreensão da importância da multidisciplinaridade dos programas e projetos dentro da organização;

1) dividir conhecimento e perícia com colegas e clientes;

m) dispor de habilidades de comunicação e ser capaz de promover a biblioteca e defender suas necessidades;

n) comunicar-se efetivamente com editores e com a indústria gráfica para promover os interesses da biblioteca;

o) reconhecer o valor da rede profissional e participar ativamente das associações profissionais;

p) perseguir ativamente o desenvolvimento pessoal e profissional através da educação continuada. (PASSOS, 2005 p.9).

Observando o conjunto de habilidades, conhecimentos, valores, comportamentos e atitudes estabelecido pela $A A L L$ e relacionando-o com o advento da Internet, das tecnologias e o avanço da ciência em todos os campos, é visível que para o campo de atuação do bibliotecário, as transformações ocorridas principalmente no âmbito das Tecnologias da Informação e Comunicação (TIC), “[...] proporcionou a 
Revista ACB: Biblioteconomia em Santa Catarina, Florianópolis, v. 22, n. 2, ESPECIAL, p. 238-256, abr./ jul., 2017. Anais do $35^{\circ}$ Painel Biblioteconomia Santa Catarina.

Chapecó

pulverização das profissões em especializações, em subdivisões e em caminhos que muitas vezes se superpõem e que, em vários casos, apresentam interseções importantes” (WALTER, 2009, p.68).

Com isso, utilizar o recurso da Internet nos trabalhos biblioteconômicos em informação jurídica exige do profissional um entendimento especializado, conforme afirma Gonçalves e Santos (2009, p. 9):

O usuário da informação de escritórios jurídicos - o profissional especializado - necessita que o bibliotecário seja detentor, além das técnicas inerentes e consolidadas que sua profissão exige, de vasto aparato tecnológico que possa suportar a informação, de conhecimento específico ou amplo - mesmo que superficial - sobre técnicas de negociações empresariais que sustentem seus métodos de tratamento da informação e a eles agreguem valor, e que atendam ao usuário com respostas rápidas, eficientes, seguras e eficazes.

Todavia, é importante que o mercado de trabalho reconheça essa competência, não somente por discursos e currículos, mas sim pelas práticas profissionais diárias que correspondem com o ofício laboral.

\section{INFORMAÇÃO JURÍDICA}

É perceptível que nos dias atuais existe uma constante mudança nas leis, emendas e afins e, por consequência, um grande acúmulo de processos jurídicos e, decorrentes destes, um volume exorbitante de literatura jurídica. Isto ocorre, segundo Passos (2004, p. 189), porque "a informação jurídica está relacionada a duas profissões muito antigas: o Direito e a Biblioteconomia".

Para tanto, “[...] a informação jurídica é elemento imprescindível para que se alcance os objetivos no âmbito jurídico" (MIRANDA, 2004, p. 138), de modo consequente, é imprescindível para um melhor desempenho no trabalho dos profissionais em Direito, sejam amparados por profissionais qualificados no manuseio, armazenamento e recuperação das informações jurídicas. Passos (2004) está de acordo com essa afirmação quando afirma que diante do

[...] espantoso volume de informações existentes na literatura jurídica, torna-se impossível ao usuário, manter-se atualizado em todos os aspectos no âmbito de seu interesse profissional. [Assim], cabe aos bibliotecários enfrentar os desafios que lhes são apresentados, procurando as formas mais práticas e eficientes para controlar essa literatura, de modo a colocá-la ao alcance dos usuários. (PASSOS, 2004, p. 79)

Entretanto, em algumas obras, a informação jurídica “[...] difere de alguns tipos de informação, em um aspecto muito importante: a longevidade" (PASSOS, 1994, p.364). Para isso, torna essencial o trabalho biblioteconômico neste âmbito documental e informacional, pois, “[...] os acervos das bibliotecas jurídicas devem estar organizados, visando à satisfação de necessidades informacionais específicas desse 
Revista ACB: Biblioteconomia em Santa Catarina, Florianópolis, v. 22, n. 2, ESPECIAL, p. 238-256, abr./ jul., 2017. Anais do $35^{\circ}$ Painel Biblioteconomia Santa Catarina.

Chapecó

público" (MIRANDA; D’AMORE; PINTO, 2013, p.100).

Ilustrando melhor o acúmulo de produções literárias jurídicas, segundo o Instituto Brasileiro de Planejamento e Tributação (IBPT), o Brasil criou 4.960.610 normas para reger a vida do cidadão brasileiro, entre emendas constitucionais, leis delegadas, complementares e ordinárias, medidas provisórias, decretos e normas complementares e outros desde que a atual Constituição Federal (1988) foi promulgada. Isso quer dizer que, em média, foram publicadas 522 normas a cada dia do período ou 782 normas por dia útil. Só de normas tributárias, são 320.343. Uma média de 46 a cada dia útil, outras 30.322 são de âmbito federal; 96.664 estadual e 193.357 municipal (INSTITUTO BRASILEIRO DE PLANEJAMENTO E TRIBUTAÇÃO, 2014).

Tendo vista essa "massa" documental, Passos (1994, p. 363) explica que "a informação jurídica pode ser gerada, registrada e recuperada, basicamente, em três formas distintas: descritivas (por meio da doutrina); normativa (pela legislação) e interpretativa (com emprego da jurisprudência) ". Sendo assim, a mesma autora expõe que "é incontestável, para qualquer sistema de informação, a importância do conhecimento da escala da literatura que tenta controlar”. (PASSOS, 1994, p. 364)

Diante deste cenário, os bibliotecários atuantes nas bibliotecas jurídicas e afins dentro de seus objetivos, devem conhecer as fontes de informação jurídicas, para proporcionar aos seus usuários um serviço eficiente e eficaz. Esclarecendo estas fontes, Miranda (2004, p. 138), informa que "[...] a informação jurídica é originada fundamentalmente por um tripé informacional: Legislação, Doutrina e Jurisprudência”.

Desta forma Miranda, D’Amore e Pinto (2013) comentam que:

[...] as bibliotecas jurídicas objetivam disseminar a informação jurídica, especialmente na esfera de suas instituições mantenedoras, com o intuito de subsidiar as decisões processuais em fluxo, como, também, auxiliar a todos os juristas na aplicação da justiça e até mesmo criar pensamento jurídico. (MIRANDA; D’AMORE; PINTO, 2013b, p.100).

Elucidando esses objetivos, Gonçalves e Santos (2009, p. 07) comentam que a biblioteca jurídica nesta perspectiva o bibliotecário atuante na área, "torna-se a condutora do conhecimento administrado, em suas vertentes, a produção e sustentação das condições propícias às tomadas de decisão, que são essenciais ao usuário que dela necessita e intenta comunicar algo".

Sendo assim, pode-se afirmar que o objetivo da documentação jurídica, portanto, "é reunir e organizar a informação jurídica, de tal forma que permita colocá-la ao alcance do usuário, no momento certo, tendo em vista os recursos disponíveis para isso". (VIEIRA, 2014, p. 205). 
Revista ACB: Biblioteconomia em Santa Catarina, Florianópolis, v. 22, n. 2, ESPECIAL, p. 238-256, abr./ jul., 2017. Anais do $35^{\circ}$ Painel Biblioteconomia Santa Catarina.

Chapecó

\section{O BIBLIOTECÁRIO JURÍDICO}

Passos (2005) relata que o bibliotecário jurídico é um profissional que tem como objetivo facilitar o acesso à informação jurídica de forma ágil e eficiente. E ainda, expõe que:

[...] as competências do bibliotecário jurídico variam de acordo com o local que trabalha (universidade, bibliotecas governamentais, escritórios de advocacia) ou mesmo em relação a sua especialização (bibliotecário de referência, indexador, no desenvolvimento da coleção). Em instituições menores onde há um ou dois profissionais contratados, o bibliotecário precisa, muitas vezes, ser o administrador, catalogador e o pesquisador" (PASSOS, 2005, p. 8).

Da mesma forma que pode atuar em diferentes locais, o bibliotecário jurídico também pode desenvolver seu trabalho em diferentes suportes, tal como físico ou virtual. Confirmando isso, Almeida Junior e Santos Neto, explanam que a mediação da informação é indispensável no serviço do bibliotecário, “[...] mesmo que ela seja realizada com ou sem a presença, imediata/física ou não dos usuários” (ALMEIDA JUNIOR; SANTOS NETO, 2014, p. 99).

Reconhecendo o trabalho prestado pelo bibliotecário em informação jurídica em relação a outras áreas de atuação da Biblioteconomia, Passos (2014) explicita que o bibliotecário jurídico “[...] atua em um nicho de mercado muito específico, aplicando teorias técnicas da Biblioteconomia ao trabalho de selecionar, adquirir, prover e disseminar informações jurídicas”. (PASSOS, 2014, p. 102).

Todavia, para realização e eficiência nos serviços prestados, o bibliotecário jurídico no seu dia a dia "[...] deve munir-se de meios realmente eficazes para o controle (acesso, tratamento e recuperação) das diferentes leis, decretos, regulamentos, portarias, resoluções e demais atos das autoridades públicas" (PASSOS, 2005, p.9).

\subsection{O perfil do Bibliotecário Jurídico}

O bibliotecário jurídico como um profissional que atua em uma área específica não pode se esquecer de que "[...] a Biblioteconomia é uma ciência social aplicada e o bibliotecário necessita também de conhecimento acerca de sua área de atuação" (BAPTISTA et al., 2008, p.153). Portanto, torna-se imprescindível que o profissional " [...] bibliotecário que trabalha nessa área necessita das habilidades e conhecimentos específicos". (BAPTISTA et al., 2008, p. 153).

De acordo com essas necessidades e considerando a complexidade e a infinidade de concepções, conceitos e particularidade da informação jurídica e com isso, a premência dos profissionais do Direito, é imprescindível que o bibliotecário desenvolva habilidades técnicas, tanto no que concerne à 
Revista ACB: Biblioteconomia em Santa Catarina, Florianópolis, v. 22, n. 2, ESPECIAL, p. 238-256, abr./ jul., 2017. Anais do $35^{\circ}$ Painel Biblioteconomia Santa Catarina.

Chapecó

Biblioteconomia e Ciência da Informação quanto ao conhecimento e à apropriação dos conceitos da área do Direito. (SILVA, 2010).

Segundo a $A A L L$ os bibliotecários jurídicos devem:

a) estar atentos às fontes de informação, independentemente de seu suporte; b) saber avaliar as vantagens e desvantagens de várias fontes de informação; c) ser capazes de organizar a informação para que possa ser localizada e utilizada, independentemente do seu suporte; d) ter proficiência no uso de fontes de informação sejam jurídicas ou não. (PASSOS; BARROS, 2009, p. 106).

Entretanto, refletindo sobre o perfil apresentado pela AALL, observa-se que no Brasil a especialização dos bibliotecários na área de gestão da informação jurídica, é precária: "não existe nenhum curso de especialização para bibliotecários em áreas específicas de conhecimento”. (BAPTISTA et al., 2008 p.153). Apenas, cursos rápidos de curta duração, principalmente oferecidos via educação à distância e/ou em eventos específicos da área.

O bibliotecário norte-americano Alvin Podboy (2000) “[...] enumerou quatro características que definem o profissional bibliotecário nos dias de hoje: Ser onipresente, porque o bibliotecário pode estar em todos os lugares ao mesmo tempo. "Isso significa que, se não estivermos pessoalmente disponíveis, nossas ferramentas devem estar prontamente acessíveis aos nossos usuários a qualquer hora e em qualquer lugar"; Ser inovador, em observar a tecnologia hoje, e determinar como será utilizada amanhã. "Nós devemos e olhamos para as práticas que foram enraizadas na tradição e ver como podemos mudálos para atender às necessidades de hoje"; Ser tradicional e moderno, pois na Biblioteconomia se utiliza de bases antigas com os recursos do novo. "Os bibliotecários de direito devem conhecer tanto o novo como o antigo"; Ser camaleão, pois a informação e tudo que cerca o trabalho do bibliotecário estão sempre numa constante mudança, e assim, o profissional não pode ser acomodado e deve sempre assumir riscos. "Bibliotecário de hoje deve estar disposto a fazer um possível erro e aceitar a responsabilidade por esse erro". "Ser congelado em uma posição significa a probabilidade de erros maiores no futuro" . (PODBOY, 2000 tradução nossa)

Todavia, analisando estes conceitos característicos relacionados ao perfil do profissional bibliotecário, e direcionando-os à visão do gestor em informação jurídica, percebe-se que existem dificuldades no que se refere à especialização deste profissional na sua área de atuação, tendo em vista, as poucas ofertas de cursos e eventos sobre informação jurídica. Porém, o bibliotecário jurídico “deve estar consciente do seu papel de intermediador no acesso a esses dados específicos, conhecendo as fontes principais para atingir o mais nobre objetivo da Biblioteconomia que é o de transmitir a informação". 
Revista ACB: Biblioteconomia em Santa Catarina, Florianópolis, v. 22, n. 2, ESPECIAL, p. 238-256, abr./ jul., 2017. Anais do $35^{\circ}$ Painel Biblioteconomia Santa Catarina.

Chapecó

(PASSOS; BARROS, 2009, p. 108).

Para alcançar tal objetivo, a atuação dos bibliotecários jurídicos pode ocorrer [...] "em bibliotecas jurídicas, universitárias, de órgãos governamentais e de escritórios de advocacia” (PASSOS; BARROS, 2009b, p. 106). Consequentemente, [...] “os usuários típicos de uma biblioteca jurídica são advogados, juízes, juristas, legisladores, professores e alunos dos cursos de direito e o cidadão comum". (PASSOS; BARROS, 2009, p. 106).

Nos cursos de Biblioteconomia no Brasil, "o recém-formado enfrenta muitas dificuldades, pois é uma área difícil para quem não tem familiaridade com a linguagem, tipos de documentos e outras particularidades da informação jurídica” (BAPTISTA et al., 2008, p. 157). Desta forma, é notório na atuação destes profissionais "[...] a necessidade de especialização, para melhor atuação nesta área, é amplamente reconhecida" (BAPTISTA et al., 2008, p. 158).

Ressaltando a importância da capacitação e relacionando com a competência em informação do profissional bibliotecário jurídico, Souza (2013) expõe que:

\begin{abstract}
a atuação nesta área exige dos profissionais competências que incluem conhecimento das especificidades de cada tipo de documento, compreensão do sistema jurídico brasileiro, da terminologia da área e dos instrumentos empregados para organização da informação. (SOUZA, 2013, p.16).
\end{abstract}

Dito isso, por meio da literatura percebe-se que a atuação do bibliotecário jurídico possui um grande desafio que se refere à " [...] rapidez com que a informação jurídica se inova torna a literatura (ainda que recente) ultrapassada e obsoleta. Ocasionando, assim, uma maior dificuldade das bibliotecas permanecerem com suas publicações sempre atualizadas”. (MIRANDA; D’AMORE; PINTO, 2013, p.96).

\title{
5 ASPECTOS METODOLÓGICOS
}

Para realização da pesquisa, utilizou-se a abordagem quantitativa e qualitativa, tanto para coletar os dados, como para o tratamento destes. A técnica utilizada foi o envio de um questionário para endereços de e-mails dos profissionais bibliotecários jurídicos pré-selecionados de Florianópolis, SC, ou seja, optou-se realizar uma amostragem não probabilística.

A amostragem não probabilística ou amostragem subjetiva é uma técnica de amostra intencional para realização da pesquisa. Oliveira (1989) diz que este tipo de amostragem, também chamada Julgamental, é chamado desta forma porque não depende de princípios científicos, mas de arbítrio. "É 
Revista ACB: Biblioteconomia em Santa Catarina, Florianópolis, v. 22, n. 2, ESPECIAL, p. 238-256, abr./ jul., 2017. Anais do $35^{\circ}$ Painel Biblioteconomia Santa Catarina.

Chapecó

uma técnica tradicional, onde a seleção, amplitude e avaliação da amostra são baseadas num critério próprio do autor, e, portanto, sua natureza é eminentemente subjetiva”. (OLIVEIRA, 1989, p. 35).

Com isso, os critérios de escolha dos profissionais respondentes foram: de bibliotecários atuantes na área de informação jurídica; de atuação somente na cidade de Florianópolis; da escolha de apenas um profissional por entidade; de desempenho da profissão em mais de um ano na entidade.

Desse modo, o questionário foi enviado aos respondentes, aplicando métodos quantitativos e qualitativos para extração dos resultados para a pesquisa. A abordagem qualitativa, de acordo com Godoy (1995, p. 21), se ocupa de "um reconhecido lugar entre várias possibilidades de se estudar os fenômenos que envolvem os seres humanos e suas intricadas relações sociais [...]". Além disso, a mesma autora expõe que para realização e aplicação da pesquisa qualitativa, o pesquisador "vai a campo buscando captar o fenômeno em estudo a partir da perspectiva das pessoas nele envolvidas”. (GODOY, 1995, p.21).

Do ponto de vista dos objetivos, esta pesquisa se caracteriza como descritiva e exploratória. Para Creswell (2010), a pesquisa descritiva proporciona o levantamento e a identificação de tendências, de atitudes ou de opiniões de uma população, a partir de uma amostra desta: utiliza-se de questionário ou de entrevistas para a coleta de dados e assim, proporcionar uma maior familiarização com uma dada temática (pesquisa exploratória).

Nesta investigação, a pesquisa exploratória é também bibliográfica. Para este fim, a busca bibliográfica foi realizada em bases de dados de artigos científicos, dissertações, teses e também em livros de diferentes autores relacionados à temática, como apoio para fundamentação conceitual. $\quad$ A busca nestas Bases de Dados foi realizada utilizando as seguintes palavras-chave: Informação Jurídica, Bibliotecário Jurídico, Competência em Informação, Competência Informacional, Perfil do Bibliotecário Jurídico, Tratamento da Informação Jurídica, Competência do Bibliotecário Jurídico. Com base nas referências e citações dos documentos obtidos nestas buscas, foi possível ampliar o número de autores que abordava sobre esta temática. Foram realizadas as pesquisas bibliográficas, no Banco de Teses da Capes, Portal de Periódicos da Capes, Periódicos UFSC, Biblioteca Digital Brasileira de Teses e Dissertações - (BDTD), SciELO e o Google Acadêmico.

A Tabela 1 apresenta a quantidade de referências bibliográficas recuperadas para a fundamentação conceitual desta pesquisa:

Tabela 1 - Referências Bibliográficas recuperadas 
Revista ACB: Biblioteconomia em Santa Catarina, Florianópolis, v. 22, n. 2, ESPECIAL, p. 238-256, abr./ jul., 2017. Anais do $35^{\circ}$ Painel Biblioteconomia Santa Catarina.

Chapecó

\begin{tabular}{|c|c|c|c|c|c|}
\hline Palavras-chave & Livros & Teses & Dissertações & Artigos & $\begin{array}{l}\text { Número total de } \\
\text { documentos } \\
\text { recuperados }\end{array}$ \\
\hline Informação Jurídica & 04 & 02 & 01 & 06 & 13 \\
\hline Bibliotecário Jurídico & 05 & 01 & 02 & 06 & 14 \\
\hline $\begin{array}{l}\text { Competência em } \\
\text { Informação }\end{array}$ & 02 & 01 & 02 & 09 & 14 \\
\hline $\begin{array}{l}\text { Perfil do bibliotecário } \\
\text { jurídico }\end{array}$ & 03 & - & 01 & 06 & 10 \\
\hline $\begin{array}{l}\text { Tratamento da } \\
\text { informação jurídica }\end{array}$ & 02 & - & - & 03 & 04 \\
\hline $\begin{array}{l}\text { Competência do } \\
\text { bibliotecário jurídico }\end{array}$ & - & - & - & 02 & 02 \\
\hline
\end{tabular}

Fonte: dados obtidos na pesquisa (2016).

O instrumento utilizado para a coleta de dados e, consequentemente, para delinear os resultados da pesquisa, foi um questionário com questões abertas, fechadas e de múltipla escolha, aplicado aos profissionais bibliotecários jurídicos.

Para proporcionar uma interação efetiva entre o informante e a análise final da pesquisa e "para facilitar o processo de tabulação de dados por meio de suportes computacionais, as questões e as respostas da pesquisa devem ser previamente codificadas". (SILVA; MENEZES, 2001, p. 34). Desta forma, o questionário foi formulado da seguinte maneira:

a) sete perguntas fechadas e de múltiplas escolhas relacionadas à formação profissional;

b) seis perguntas fechadas e de múltiplas escolhas sobre a atuação profissional;

c) duas perguntas de múltiplas escolhas buscando informações sobre as tarefas desempenhadas por estes profissionais;

d) uma pergunta fechada com 13 subitens abordando as competências e habilidades destes profissionais; e

e) uma pergunta aberta acerca da atuação do bibliotecário na área jurídica.

O questionário elaborado foi aplicado em órgãos públicos situados na cidade de Florianópolis, SC, especificamente em sua biblioteca e/ou setores a fim, com o bibliotecário jurídico, gestor da unidade de informação. Para fins de comparação do tema abordado, a aplicação do questionário foi também realizada em uma Instituição privada. A amostra consistiu de 10 bibliotecários, sendo este de setores públicos e privados.

\section{RESULTADOS}


Revista ACB: Biblioteconomia em Santa Catarina, Florianópolis, v. 22, n. 2, ESPECIAL, p. 238-256, abr./ jul., 2017. Anais do $35^{\circ}$ Painel Biblioteconomia Santa Catarina.

Chapecó

Para os resultados desta pesquisa e quanto às questões fechadas e de múltipla escolha (quantitativa), optou-se em apresentar de forma descritiva e em gráficos. E em relação às questões abertas (qualitativa), estas estão apresentadas na forma descritiva.

Para as questões abertas, foi utilizada a técnica de análise de conteúdo, com base em Bardin (2011, p. 182), cujo “[...] objetivo é valorizar e tratar da forma mais automática possível a informação textual original, sem transformação nem codificação, nem redução a priori da informação de base".

\subsection{Formação dos profissionais da área jurídica}

Para a informação sobre o ano de formação acadêmica, foi utilizada uma questão aberta. Com isso, percebeu-se que 50\% dos respondentes obtiveram sua formação em Biblioteconomia entre os anos 2001 a 2016; 40\% com formação entre os anos de 1981 a 1990; e 10\% entre os anos de 1991 a 2000. O que demonstra um profissional formado, em média, no século atual e, por este motivo, com maior proximidade a conteúdos atuais da área.

Além da formação em Biblioteconomia, foi questionado aos respondentes se possuíam graduação em Direito. Constatou-se que $80 \%$ dos profissionais possuem apenas a graduação em Biblioteconomia e $20 \%$ possuem graduação em Direito. Ainda assim e, de acordo com Silva (2010), a formação em Biblioteconomia carece de uma especialização na área do Direito e, de modo recíproco, a formação em Direito demanda uma formação básica em Biblioteconomia.

Debatendo sobre os cursos de especialização, notou-se que $70 \%$ dos respondentes possuem cursos de pós-graduação e $30 \%$ não possuem. Os cursos de pós-graduação que estes profissionais realizaram foram: Mestrado em Administração; Informática Jurídica; Gestão da Informação; Inovação Tecnológica; Gestão de Bibliotecas e Direito Constitucional. Em relação ao conhecimento de outros idiomas, constatou-se que $80 \%$ dos profissionais possuem conhecimento na língua inglesa entre o nível básico, médio avançado. Cabe ressaltar que $20 \%$ dos respondentes possuem conhecimento também em outros idiomas.

Levantado questionamento sobre cursos de especialização na área jurídica, descobriu-se que 40\% dos respondentes possuem curso de capacitação em: Indexação; Pesquisa em banco de dados jurídico; Estudos Judiciários e Criminalidade; O Direito no terceiro milênio; Gestão pública e Lei de responsabilidade Fiscal e Direito empresarial. E $60 \%$ dos profissionais não possuem nenhum curso de especialização na área jurídica. 
Revista ACB: Biblioteconomia em Santa Catarina, Florianópolis, v. 22, n. 2, ESPECIAL, p. 238-256, abr./ jul., 2017. Anais do $35^{\circ}$ Painel Biblioteconomia Santa Catarina.

Chapecó

Sobre a forma como os respondentes se mantêm atualizados nos assuntos relacionados à área do Direito, constatou-se que $7 \%$ utilizam cursos para se atualizar $14 \%$ por meio de eventos, $21 \%$ por meio da leitura de livros e/ou periódicos especializados, $34 \%$ por intermédio de sites jurídicos, $21 \%$ com trocas de conhecimentos e experiências com colegas da mesma área de atuação e 3\% por outros meios.

\subsection{Atuação dos profissionais}

Ao serem questionados sobre quais instituições no município de Florianópolis, SC que os profissionais respondentes desta pesquisa atuam, identificaram-se os seguintes locais: em centros de estudos; na Secretaria de Administração do Estado de SC; na Biblioteca de Escola Superior de Magistratura do Estado de SC; na Justiça Federal; no Tribunal de Justiça; na Assembleia Legislativa de Santa Catarina; na Eletrosul Centrais Elétricas S/A e, em escritórios de advocacia. Estes profissionais atuam em média oito anos na área da informação jurídica.

Explicitando o tempo total de atuação na área jurídica de cada respondente, identificou-se que $10 \%$ atuam menos de um ano, $40 \%$ atuam de um a cinco anos, $10 \%$ de seis a dez anos e $20 \%$ de onze a quinze anos e dezesseis anos ou mais.

Questionando se os respondentes antes de conceber a graduação em Biblioteconomia, se tiveram algum contato com a área jurídica, observou-se que: $60 \%$ tiveram contato, por meio de estágio obrigatório e extracurricular e outros e $40 \%$ não tiveram nenhum contato antes da formação profissional, o que denota, para este último dado, a entrada no mercado de trabalho na área jurídica de maneira inexperiente.

Com isto, reafirma o apontamento de Baptista et al., (2008), na constatação que no Brasil a especialização dos profissionais bibliotecários jurídicos, é precária e que não existe nenhum curso de especialização para bibliotecários em áreas específicas de conhecimento, tal como a área jurídica.

Sobre a participação em projetos/atividades como bibliotecário jurídico, os respondentes informaram que $31 \%$ são nas atividades de práticas diárias, $21 \%$ respectivamente em apoio/ suporte a outros profissionais e projetos na própria Unidade de Informação onde atuam, 15\% na assistência documental e informacional, $6 \%$ em projetos em rede de bibliotecas da instituição e de modo recíproco, $3 \%$ em publicações de trabalhos em livros e/ou periódicos e apresentação de trabalho em eventos.

\subsection{Tarefas desempenhadas pelos profissionais}

As principais tarefas desempenhadas pelos profissionais respondentes nesta pesquisa em seu ambiente de trabalho são: $24 \%$ no tratamento da informação (classificação, catalogação e indexação); 
Revista ACB: Biblioteconomia em Santa Catarina, Florianópolis, v. 22, n. 2, ESPECIAL, p. 238-256, abr./ jul., 2017. Anais do $35^{\circ}$ Painel Biblioteconomia Santa Catarina.

Chapecó

$19 \%$ na disseminação seletiva da informação; $17 \%$ na coleta e organização de legislação; também com $17 \%$ na atividade de pesquisa; $14 \%$ na manutenção de serviços prestados online; $7 \%$ acompanhamento de jurisprudência e; $2 \%$ em outras atividades.

Desta forma, percebe-se que estes resultados são condizentes com a observação de Silva (2010), em apontar que é imprescindível que o bibliotecário desenvolva habilidades técnicas, tanto no que concerne à Biblioteconomia e Ciência da Informação quanto ao conhecimento e à apropriação conceitos da área do Direito.

Dentro dessas atividades e/ou projetos desempenhados na atuação como bibliotecário jurídico, foi questionado aos participantes da pesquisa quais as dificuldades que estes encontravam para execução dessas atividades. Os profissionais responderam: 29\% não encontram dificuldade; 22\% apresentam dificuldade para entender a linguagem jurídica; $21 \%$ sentem falta de um curso de especialização na área e falta de noções básicas sobre o Direito; $7 \%$ dos profissionais encontram dificuldades pelo desconhecimento das fontes de informação jurídica e também de idiomas estrangeiros.

Portanto, estes resultados validam a reflexão de Baptista et al. (2008) e Souza (2010), no qual comentam que o recém-formado do curso de Biblioteconomia enfrenta dificuldades para atuar na área de informação jurídica, pois não tem tanto familiaridade com a linguagem específica do Direito, quanto com os tipos de documentos e outras singularidades da área jurídica. Sendo assim, a atuação do profissional bibliotecário é exigida em sua atuação nesta área, competências que incluem conhecimentos específicos para cada tipo de documento, linguagens e compreensão do sistema jurídico brasileiro, que vão deste a terminologia da área aos instrumentos empregados para organização da informação.

\subsection{Competência dos profissionais}

Baseado na definição da AALL em relação à competência necessária ao bibliotecário jurídico e de acordo com a área de atuação dos bibliotecários respondentes foi apresentadas algumas habilidades, conhecimentos, valores, atitudes, comportamentos, entre outros, desempenhados pelos profissionais (ver tabela 2): 
Revista ACB: Biblioteconomia em Santa Catarina, Florianópolis, v. 22, n. 2, ESPECIAL, p. 238-256, abr./ jul., 2017. Anais do $35^{\circ}$ Painel Biblioteconomia Santa Catarina.

Chapecó

Tabela 2 - Competência dos Respondentes

\section{COMPETÊNCIA REQUERIDA}

Conhecimento do sistema legal do país
Conhecimento da profissão jurídica (Direito)

Conhecimento das fontes de informação
jurídica (legislação, jurisprudência e doutrina)

Conhecimento da terminologia jurídica

Saber onde buscar informação jurídica

Conhecimento das necessidades dos usuários

$\begin{array}{lcc}\text { Implementar princípios administrativos } & 70 \% & 30 \% \\ \text { Senso crítico } & 100 \% & \\ \text { Facilidade de comunicação } & 100 \% & \\ \text { Saber trabalhar em grupo } & 90 \% & 10 \% \\ \text { Saber lidar com tecnologias } & 90 \% & 10 \% \\ \text { Preocupação com a educação continuada } & 60 \% & 40 \%\end{array}$

Participação ativa na produção científica sobre
informação jurídica

Fonte: Dados obtidos na pesquisa (2016)

A tabela 2 apresenta alguns resultados que merecem destaque: percebe-se que ao considerarem que "são competentes em", todos bibliotecários respondentes afirmam unanimemente que são profissionais com senso crítico e possuem facilidade de comunicação, tanto com os colegas de trabalho, quanto com os usuários; é perceptível que a maioria dos respondentes afirma que são profissionais que sabem trabalhar em grupo, de lidar com tecnologias, de saber onde buscar informações jurídicas dispõe de Conhecimento das fontes de informação jurídica (legislação, jurisprudência e doutrina) e de terem a consciência da importância da educação continuada. Ainda assim, apenas 30\% declaram participarem ativamente na produção científica sobre informação jurídica.

Por outro lado, quanto a considerar "importante desenvolver", constata-se que os respondentes declaram que consideram "possuir estas competências", expõem um índice baixo na importância no desenvolvimento destas atividades na atuação profissional atual, tendo em vista, a efetivação continua destas competências no dia a dia laboral. Diferentemente, tornam mais relevante à importância e a carência de desenvolverem uma participação ativa na produção científica sobre informação jurídica. Comprovando assim, o que foi discutido neste artigo a carência de produções científicas sobre o assunto abordado nesta pesquisa. 
Revista ACB: Biblioteconomia em Santa Catarina, Florianópolis, v. 22, n. 2, ESPECIAL, p. 238-256, abr./ jul., 2017. Anais do $35^{\circ}$ Painel Biblioteconomia Santa Catarina.

Chapecó

\section{CONSIDERAÇÕES FINAIS}

Este artigo abordou a competência em informação Jurídica dos bibliotecários de Florianópolis, SC, evidenciando conceitos associados ao perfil e atuação destes profissionais no mercado de trabalho.

Percebeu-se que o bibliotecário é importante e essencial para a organização, tratamento e disseminação da informação jurídica, e que, devido à complexidade do vocabulário especifico da área do Direito, o bibliotecário atuante neste mercado deve buscar o conhecimento especializado para atender estes usuários.

Entretanto, apesar da importância do bibliotecário no suporte aos trabalhos jurídicos, seu perfil ainda é pouco conhecido, devido à carência de produção científica a respeito do tema, constatado na pesquisa realizada para a pesquisa.

Destaca-se que a maioria dos profissionais respondentes possui experiência média de oito anos de atuação na área em Florianópolis, SC, e que os mesmos adquiriram capacitação por meio da experiência do dia a dia de trabalho e convívio com os profissionais de Direito, bem como pela formação, capacitação e experiência vivenciada em sua atuação em informação jurídica. Fica evidente, de acordo com esses profissionais, que não há necessidade de obter graduação em Direito para melhor desenvolver seu trabalho. Contudo, é preciso que o profissional se especialize e busque ampliar seus conhecimentos por meio de cursos, eventos e trocas de experiências com colegas da área.

O mercado de trabalho em Biblioteconomia jurídica em Florianópolis, SC tem um vasto campo de atuação e é perceptível, após a realização desta pesquisa que a instabilidade profissional para esses bibliotecários respondentes é evidente. Isto posto, afirma-se que a opção de atuar, capacitar e dedicar-se a oferecer trabalhos biblioteconômicos na área de informação jurídica é presente no mercado de trabalho em Santa Catarina.

O perfil profissional do bibliotecário está sempre em constantes mudanças, devido às novas tecnologias e o surgimento de outras demandas trabalhistas. Em especial atenção aos profissionais da informação jurídica, pois é uma área de constante mudança, atualizações e modificações. Esta área de atuação possui usuários que buscam suporte biblioteconômico com qualidade e prestação de serviços eficazes e eficientes em relação á disseminação, recuperação e tratamento da informação.

Vista disso, o bibliotecário jurídico necessita acompanhar essa realidade, por meio de uma busca ininterrupta pelo aperfeiçoamento e desenvolvimento da competência em informação nesta área. 
Revista ACB: Biblioteconomia em Santa Catarina, Florianópolis, v. 22, n. 2, ESPECIAL, p. 238-256, abr./ jul., 2017. Anais do $35^{\circ}$ Painel Biblioteconomia Santa Catarina.

Chapecó

Entretanto, o aprofundamento da competência em informação para esses profissionais ainda é algo a ser estudado em futuras pesquisas, talvez em comparação em nível estadual, regional e/ou nacional, tendo em vista a limitada produção científica sobre o tema.

Finalizando, expõe-se que após realização desta pesquisa percebe-se a importância e a carência do recém-formado em Biblioteconomia, na necessidade da atenção da academia quanto à formação e ao aprimoramento do bibliotecário que atua na área jurídica, tendo vista que é um profissional essencial nas bibliotecas, assessorias e instituições (privadas e públicas) da área jurídica, devido à qualidade de seus serviços informacionais, ao suporte e nos subsídios em informação jurídica.

\section{REFERÊNCIAS}

ALMEIDA JUNIOR, Oswaldo Francisco de; SANTOS NETO, João Arlindo dos. Mediação da Informação e a Organização do conhecimento: interrelações. Informação \& Informação, Londrina, v. 19, n. 2, p.98-116, maio 2014. Disponível em: <http://www.uel.br/revistas/uel/index.php/informacao/article/view/16716/pdf_25>. Acesso em: 04 mar. 2017.

BARDIN, Laurence. Análise de Conteúdo. Lisboa: Edições 70, 1977. 225 p.

BAPTISTA, Sofia Galvão et al. O perfil do bibliotecário que atua na área jurídica: relato de pesquisa. Revista Ibero-americana de Ciência da Informação, Brasília, v. 1, n. 2, p.151-174, dez. 2008. Disponível em: <http://periodicos.unb.br/index.php/RICI/article/viewFile/809/2356>. Acesso em: 31 ago. 2016.

BELLUZZO, Regina Célia Baptista; FERES, Glória Georges. Competência em informação, redes de conhecimento e as metas educativas para 2021: reflexões e inter-relações. In: BELLUZZO, Regina Célia Baptista; FERES, Glória Georges; VALENTIN, Maria Lígia Pomim (Org.). Redes de conhecimento e competência em informação: Interface da gestão, mediação e uso da informação. Rio de Janeiro: Interciência, 2015. p. 01-35.

CRESWELL, John W. Projeto de pesquisa: métodos qualitativo, quantitativo e misto. 3. ed. Porto Alegre: Artmed, 2010.

DUDZIAK, Elisabeth Adriana. Information Litaracy: princípios, filosofia e prática. Ciência e Informação, Brasília, v. 32, n. 1, p.23-55, jan. 2003. Disponível em: <http://revista.ibict.br/ciinf/article/view/1016/1071>. Acesso em: 04 mar. 2017.

GODOY, Arilda Schmidt. Pesquisa qualitativa: tipos fundamentais. Revista de Administração de Empresas, São Paulo, p.20-31, maio 1995. Disponível em: <https://pt.scribd.com/document/66104133/Pesquisa-Qualitativa-TiposFundamentais>. Acesso em: 05 out. 2016.

GONÇALVES, Marcos Rogério; SANTOS, Valéria Silva. A Biblioteca Jurídica como fonte de conhecimento decisório. Crb-8 Digital, São Paulo, v. 2, n. 2, p.4-11, set. 2009. Disponível em:

<http://www.revista.crb8.org.br/index.php/crb8digital/article/view/2/2.>. Acesso em: 24 out. 2016.

MELO, Ana Virgília Chaves de; ARAÚJO, Eliany Alvarenga de. Competência informacional e gestão do conhecimento: uma relação necessária no contexto da sociedade da informação. Perspectivas em Ciência da Informação, Belo Horizonte, v. 12, n. 2, p.185-201, maio 2007. Disponível em:

<http://portaldeperiodicos.eci.ufmg.br/index.php/pci/article/view/49>. Acesso em: 22 out. 
Revista ACB: Biblioteconomia em Santa Catarina, Florianópolis, v. 22, n. 2, ESPECIAL, p. 238-256, abr./ jul., 2017. Anais do $35^{\circ}$ Painel Biblioteconomia Santa Catarina.

Chapecó

MIRANDA, Ana Cláudia Carvalho de; D`AMORE, Ticiano Maciel; PINTO, Virginia Bentes. Gestão documental da informação jurídica. Perspectivas em Ciência da Informação, Belo Horizonte, v. 18, n. 3, p.96-110, jul. 2004. Disponível em: <http://portaldeperiodicos.eci.ufmg.br/index.php/pci/article/view/1710>. Acesso em: 31 ago. 2016.

MIRANDA, Silvânia Vieira. Identificando competências informacionais. Ciência da Informação, Brasília, v. 33, n. 2, p.112-122, maio 2004. Disponível em: 〈http://www.scielo.br/pdf/ci/v33n2/a12v33n2.pdf〉. Acesso em: 31 ago. 2016

OLIVEIRA, Francisco Neves. Técnicas de amostragem utilizadas pelos serviços de auditoria interna de empresas no Brasil: um estudo de caso. 1989. 156 f. Dissertação (Mestrado) - Curso de Ciências Contábeis, Fundação Getúlio Vargas - Instituto Superior de Estudos Contábeis, Rio de Janeiro, 1989. Disponível em: <http://bibliotecadigital.fgv.br/dspace/bitstream/handle/10438/9206/000081542.pdf?sequence=1>. Acesso em: 13 mar. 2017.

PASSOS, Edilenice; BARROS, Lucivaldo Vasconcelos. Fontes de informação para pesquisa em direito. Brasília: Briquet de Lemos, 2009. 170 p.

PASSOS, Edilenice. O Futuro da Biblioteca Jurídica. Infolegis, Brasília, v. 2, n. 2, p.1-22, maio 2005. Disponível em: <http://www.infolegis.com.br/wa_files/futuro-biblioteca-juridica.pdf>. Acesso em: 31 ago. 2016.

PASSOS, Edilenice Jovelina Lima. O controle da informação jurídica no Brasil: a contribuição do Senado Federal. Ciência da Informação, Brasília, v. 23, n. 3, p.363-368, dez. 1994. Disponível em:

<http://revista.ibict.br/ciinf/article/view/537>. Acesso em: 31 ago. 2016.

PASSOS, Edilenice (Org.). Informação Jurídica: teoria e prática. Brasília: Thesaurus, 2004. 237 p.

PASSOS, Edilenice; WALTER, Maria Tereza Machado Teles. O mercado de trabalho para o bibliotecário jurídico no Poder Legislativo federal e nos tribunais superiores. Cadernos de Informação Jurídica, Brasília, v. 1, n. 1, p.14-49, jan. 2014. Disponível em: <http://www.egov.ufsc.br/portal/conteudo/o-mercado-de-trabalho-para-obibliotecário-jurídico-no-poder-legislativo-federal-e-nos>. Acesso em: 04 mar. 2017.

PODBOY, Alvin. React or Die: Librarians Must Innovate to Survive. 2000. Disponível em: <http://ltnarchive.hotresponse.com/july00/library_administration_p34.html>. Acesso em: 04 mar. 2017.

SILVA, Andréia Gonçalves. Fontes de informação jurídica: Conceitos e técnicas de leitura para o profissional da informação. Rio de Janeiro: Interciência, 2010. 227 p.

SILVA, Edna Lúcia da; MENEZES, Estera Muszkat. Metodologia da pesquisa e elaboração de dissertação. 3. ed. Florianópolis: Laboratório de Ensino A Distância da Ufsc, 2001. 121 p.

SMIT, Johanna W.; BARRETO, Aldo de Albuquerque. Ciência da Informação: base conceitual para a formação do profissional. In: VALENTIM, Marta Lígia (Org.). Formação do profissional da informação. São Paulo: Polis, 2002. p. 9-23. Disponível em: <http://docslide.com.br/documents/smit-jw-barreto-a-ciencia-da-informacao-baseconceitual-para-a-56d4c2bf9c339.html\#>. Acesso em: 04 mar. 2017.

SOUZA, Simone Torres de. A caracterização do documento jurídico para a organização da informação. 2013. 212 f. Dissertação (Mestrado) - Curso de Biblioteconomia, Ciência da Informação, Universidade Federal de Minas Gerais, Belo Horizonte, 2012. Disponível em:

<http://www.bibliotecadigital.ufmg.br/dspace/bitstream/handle/1843/ECIC-

9CAHBP/disserta_____simone_torres_texto_final.pdf? sequence=1.>. Acesso em: 04 mar. 2017.

TRIBUTAÇÃO, Instituto Brasileiro de Planejamento e. Brasil cria, em média, 46 novas regras de tributos a cada dia útil. 2014. Disponível em: <http://www.ibpt.com.br/noticia/1951/Brasil-cria-em-media-46-novas-regras-detributos-a-cada-dia-util>. Acesso em: 24 out. 2016.

WALTER, Maria Tereza Machado Teles. Imagens profissionais e a percepção dos bibliotecários no Brasill: uma síntese de resultados. Senatus, Brasília, v. 7, n. 1, p.68-80, jul. 2009. Disponível em: 
Revista ACB: Biblioteconomia em Santa Catarina, Florianópolis, v. 22, n. 2, ESPECIAL, p. 238-256, abr./ jul., 2017.

Anais do $35^{\circ}$ Painel Biblioteconomia Santa Catarina.

Chapecó

<http://www2.senado.leg.br/bdsf/bitstream/handle/id/182032/imagens_proficionais_bibliotecarios.pdf?sequence=1 >. Acesso em: 20 out. 2016.

VIEIRA, Ronaldo. Introdução à teoria geral da biblioteconomia. Rio de Janeiro: Interciência, 2014. 305 p.

VITORINO, Elizete Vieira. A perspectiva da competência informacional na educação a distância (EAD). Informacao \& Sociedade, João Pessoa, v. 19, n. 2, p.37-44, maio 2009. Disponível em: <http://www.ies.ufpb.br/ojs/index.php/ies/article/view/1834>. Acesso em: 22 out. 2016.

VITORINO, Elizete Vieira; PIANTOLA, Daniela. Competência informacional - bases históricas e conceituais: construindo significados. Ciência da Informação, Brasília, v. 38, n. 3, p.130-141, set. 2009. Disponível em: <http://www.scielo.br/pdf/ci/v38n3/v38n3a09.pdf.>. Acesso em: 23 out. 2016.

\section{THE COMPETENCE IN LEGAL INFORMATION OF THE LIBRARIANS OF FLORIANÓPOLIS, SC}

He extensive and diversified number of legal documents and their complexity represent challenges for information professionals and, consequently, require adequate training, dedication to work and clear librarianship techniques, aiming at organization, dissemination, quality in the service provided, therefore competence in information. In this sense, this research aims to investigate a competence in the legal area, in the job market of Florianópolis, SC. As a theoretical reference to base theme, the subjects addressed were: legal information, profile and role of the librarian in the legal area, and competence in information. It is a research with quantitative and also qualitative, descriptive, exploratory and bibliographic approach. A questionnaire was applied to librarians from the legal area of public and private institutions. It is concluded that the profile of the librarian of the legal area in the city of Florianópolis, SC is constituted by the training, qualification and experience in his/her work in legal information. It was noticed the need and the importance of the academy to give attention regarding the training and improvement of the legal librarian for the recent graduates in Librarianship.

Keywords: Legal Information. Legal librarian. Information literacy. Job market.

\section{GENILSON GERALDO}

Graduando do Curso de Biblioteconomia do Centro de Ciências da Educação da Universidade Federal de Santa Catarina (UFSC). Trabalha na Assessoria Jurídica da Eletrosul Centrais Elétricas, como assistente jurídico com especialidade em Análise e Distribuição de intimações judiciais, petições iniciais, assistência e suporte aos processos jurídicos, em busca de informações e documentos como subsídios de defesas em prol da empresa. Vice-Coordenador do Grupo Especializado em Bibliotecas Públicas - GEBP, da Associação Catarinense de Bibliotecários - ACB. E-mail: genilsongeraldo.biblio@gmail.com

\section{ELIZETE VIEIRA VITORINO}

Doutora em Engenharia de Produção pela Universidade Federal de Santa Catarina (UFSC). Mestra em Engenharia de Produção pela Universidade Federal de Santa Catarina (UFSC). Graduada em Biblioteconomia pela Universidade Federal de Santa Catarina (UFSC). Professora do Departamento de Ciência da Informação (CIN), Centro de Ciências da Educação (CED), da Universidade Federal de Santa Catarina, Curso de Biblioteconomia. Professora Pesquisadora do Programa de PósGraduação em Ciência da Informação (PGCIN) em nível de mestrado e doutorado. Líder do Grupo de Pesquisa GPCIn Competência em Informação, cadastrado no CNPq e certificado pela UFSC. Concluiu estágio pós-doutoral, financiado pela CAPES, na Faculdade de Letras (FLUP), da Universidade do Porto (UP), Portugal, no período de jan. 2015 a jan. 2016. E-mail: elizete.vitorino@ufsc.br 